In the clear dawn of the new political day we shall perceive the outlines of the coming service-state, and shall behold the physician, pill-bags and scalpels for the moment aside, in the front ranks of the "forward looking" men of the time, doing service with the master-builders.

William Y. WARD, M.D., Ivanhoe, Texas.

\section{TREATMENT OF INFLUENZA}

To the Editor:-During the recent epidemic of influenza I saw a great number of cases in which one of the most prominent symptoms was hemorrhage from the nose, which lasted usually several days and was often profuse. What struck me in these cases was that none of the patients developed pneumonia and all recovered. . . . Does this bleeding give us a hint to employ bloodletting more frequently in cases in which pneumonia is suspected or beginning to develop?

Julius Martinson, M.D., New York.

To the Editor:-Having passed through a severe epidemic of influenza here we are sure that there have been some important things left unsaid concerning the nature and treatment of this disease. . . . The patient should breathe pure warm air, instead of cold air, which is the popular teaching at this time. With the patient extremely prostrated and perspiring and a further complication with bronchitis, it is certainly a contraindication to apply in the sick room the open air treatment: With the given pathologic condition, the cold air treatment will certainly prove a failure. The patient should breathe cold air in the febrile stage, but should avoid it by all means when that stage passes. The prostration requires rest in bed, and judicious medical stimulation and attention to dietetics.

W. E. NeIberGer, M.D., Bloomington, Ill.

\section{"TOMATO LEAVES AND DERMATITIS"}

To the Editor:-In The Journal, Oct. 5, 1918, Dr. E. S. Lain of Oklahoma has a paper on "Dermatitis Lycopersicum Esculentum (Tomato Plant)." $\mathrm{He}$ calls the tomato "one of our most harmless and luscious vegetables." A few years ago there appeared in the Correspondenz-Blatt für schweizer Aerzte an observation of several cases of hematuria following the eating of tomatoes. Dr. Lain cites authors who attribute the dermatitis to individual susceptibility and even "anaphylactic reaction of a seisitized person." Is there not another possibility that would at the same time explain the cases of hematuria? The doctor says that the tomato belongs to the Solanaceae, nightshades, and mentions several other representatives of this group. But he forgot the most important one, the Solanum tuberosum, the potato. This, too, contains a poison in the eyes of the tuber that is removed in boiling. Every farmer knows how sensitive the potatoes are to the conditions of soil, of climate, rain and sun, place of growth, etc., as to development, taste, etc. The same is true of other peculiarities of other nightshades. The nettles, another representative, for example, may be handled with impunity in some places; in others, the slightest touch will have very painful consequences.

The following conclusions may be drawn: 1. The tomato is not under all circumstances "one of our most harmless vegetables." 2. The plant, as well as the fruit, may under certain not yet investigated conditions produce substances that are decidedly toxic to the skin and kidneys, and maybe to other tissues.

JacQues Holinger, M.D., Chicago.

\section{DEVICES FOR DISABLED MEN}

To the Editor:-I am sending to you the descriptions of some devices for men having lost one or both arms. They are founded on the last four years of experience among wounded and disabled men in England, and are the work of Dr. Arthur E. Shipley, vice chancellor of Cambridge University, who is now touring this country with the British Educational Mission.

The man who has lost an arm is usually sensitive about it, and does not like to attract attention, especially in public.

Among other difficulties are those of cornering food on the ordinary plate. For this purpose Dr. Shipley has designed a plate with an overhanging lip and also a special plate that enables the patient to get the last drop of soup without tilting the plate, a feat that would be impossible for a one-armed man.

For convenience of commerce it has been suggested that the plates should be named, and "Unimanus" has been suggested

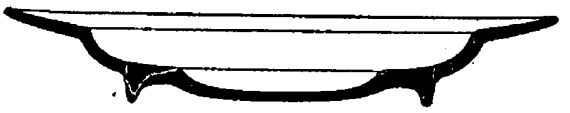
(cf. Livy 35, 21 and 41,21 ), but Dr. Shipley believes that it seems simpler and is certainly siorter to call them "manchot" plates.

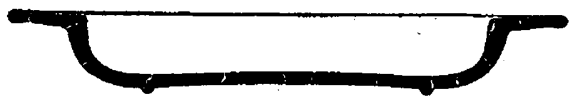

Fig. 1.-Cross-sections of plates devised for persons deprived of the use of one arm: The upper plate is a soup plate with a depression in the center from which the last two or three spoonfuls of soup can be easily removed. The lower plate is for solid food, and has vertical sides and an overhanging rim. Against this, pieces of meat or pudding can be pushed with. out any risk of their toppling over the edge.
The plates hàve been made in several styles, some as cheaply as possible, and all may be obtained of Messrs. Thomas Goode \& Co., 19 South Audley $\mathrm{St} \mathrm{r}$ e e t, London. Messrs. Goode, who are solely financially responsible, have kindly consented to devote rather more than 20 per cent. of the profits to the Serbian Relief Fund.

When the patient has been unfortunate enough to lose both arms, he has not even the solace of reading, and the device

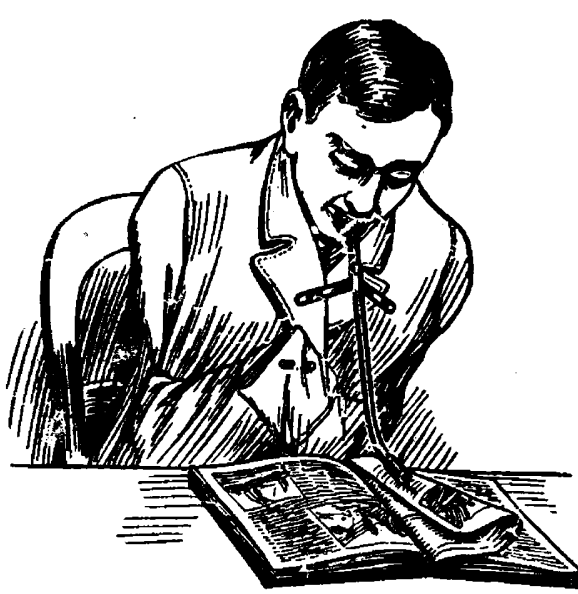
illustrated enables him to turn over the pages of a book without calling in assistance. The disk which he holds in his teeth is made of rubber, and the shaft is aluminum with a light rubber tip.

If one may learn from the enemy, a good suggestion can be obtained from the fork that is specially made for the kaiser. The outside prong contains a cutting edge which transforms it into a combination knife and fork, and so obviates the use of the knife with the other hand. These would have to be made right or left handed.

Fig. 2.-Device fot enabling an armless person to turn the pages of a book.

I am sure there are many other devices which could render the life of the one armed, or otherwise disabled, much less difficult.

R. TAIt McKenzIE, M.D., Philadelphia.

\section{AN INTERNATIONAL MEDICAL COUNCIL FOR THE RECONSTRUCTIVE PERIOD}

To the Editor:-With the termination of actual hostilities, new problems will confront the medical profession in three main directions: (1) physical fitness; (2) the increased incidence of certain infective diseases, and (3) the insanitary, pestilential conditions resulting from the war. 